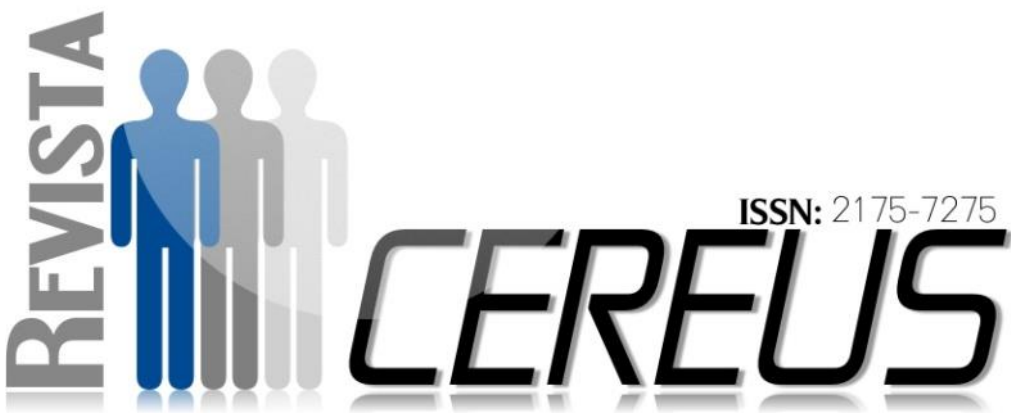

\section{O MODELO DE HÉLICE TRIPLA NO ENSINO SUPERIOR PÚBLICO E PRIVADO}

\section{RESUMO}

REIS, José Eduardo dos ${ }^{1}$ SILVA, Antonio Carlos Lopes ${ }^{2}$ FARIA, Leandro Innocentini Lopes de ${ }^{3}$ As relações entre universidades, empresas e governo estão mostrando que as universidades, além de suas clássicas atividades de ensino e pesquisa, estão incorporando uma terceira atividade: a atuação no desenvolvimento econômico local e regional, onde o financiamento público para a universidade está condicionado à sua contribuição direta para a economia. O trabalho tem como guia a discussão da hipótese de que as atividades de ensino, pesquisa e extensão ocorrem no ensino superior público e privado e podem ser explicadas pelo Modelo de Hélice Tripla, de formas diferentes. Dentro deste contexto, o presente trabalho buscou verificar, através de um estudo de caso em duas Instituições de Ensino Superior (IES) de São Carlos-SP, sendo uma pública e outra

\footnotetext{
${ }^{1}$ Doutorando na Universidade Federal de São Carlos - UFSCar, no Programa de Pósgraduação em Ciência, Tecnologia e Sociedade (CTS). Possui Mestrado em Ciência, Tecnologia e Sociedade (CTS) pela Universidade Federal de São Carlos (UFSCar), .

2 Mestre pelo Programa de Pós-Graduação em Ciência, Tecnologia e Sociedade, Área Gestão Tecnológica, da UFSCar (2011).

${ }^{3}$ Professor Adjunto da Universidade Federal de São Carlos (UFSCar)
}

v. 9, n. 3, set/dez. 2017 UnirG, Gurupi, TO, Brasil 
privada, como ocorrem as parce rias em Hélice Tripla. O método de pesquisa utilizado foi o estudo de caso documental e exploratório, e a unidade de análise compreendeu documentos relativos a Programas de Extensão das duas IES. Como resultado da pesquisa, foi possível identificar como se apresentam as parcerias em Hélice Tripla nas IES, partindo de características apresentadas no Modelo; verificar como as parcerias beneficiam os agentes representados pelas três pás; e verificar como a sociedade é atingida pelas atividades da academia (extensão). Conclui-se que a discussão dos resultados alcançados pode contribuir para a compreensão da problemática em torno dos estudos sobre a Metodologia de Hélice Tripla nas IES brasileiras.

Palavras chave: Modelo de Hélice Tripla; Universidadeindústria-governo; Instituições de Ensino Superior Públicas e Privadas.

\section{THE MODEL OF TRIPLE HELICLE IN PUBLIC AND PRIVATE HIGHER EDUCATION.}

\section{ABSTRACT}

The relations between universities, companies and government show that universities, in addition to their classic teaching and research activities, are incorporating a third activity: the performance in local and regional economic development, in which public funding for the university is conditioned to its contribution to the economy. The work guides the discussion of the hypothesis that teaching, research and extension activities occur in public and private higher education and can be explained by the Triple Helix Model, in different ways. In this context, the present work sought to verify, through a case study in two Institutions of Higher Education (HEI), located in the city of São Carlos-SP, being one public and one private, how are the partnerships in 
Triple Helix. The research meth od used was the documentary and exploratory case study, and the analysis unit comprised documents related to Extension Programs in HEI. As a result of the research, it was possible to identify how the Triple Helix partnerships in $\mathrm{HEI}$ are presented, starting from the characteristics presented in the Model; Verify how partnerships benefit the agents represented by the three blades; And to verify how society is affected by the activities of the academy (extension). It is concluded that the discussion of the results achieved can contribute to the understanding of the problematic around the studies on the Triple Helix Model in Brazilian.

Keywords: Triple Helix Model; University-industrygovernment; Public and Private Higher Education Institutions. 


\section{INTRODUÇÃO}

Considerado um dos temas importantes abarcados nos estudos da Ciência, Tecnologia e Sociedade (CTS), o Construtivismo Social, assunto de interesse de historiadores, filósofos e sociólogos, assume posição e defende que fatores sociais devem desempenhar papel de destaque na definição e aceitação de novas teorias científicas. Destaca-se, dentro das fronteiras teóricas do Construtivismo Social, temas tais como a Abordagem Normativa da Ciência; a Sociologia do Conhecimento; a Teoria Ator-Rede (TAR); a Teoria Crítica da Tecnologia; e - Modelo Hélice Tripla. Este artigo destacará o Modelo Hélice Tripla, que envolve três atores ou instituições: Universidades, Empresas e o Governo, norteados por um objetivo comum, que é o desenvolvimento da pesquisa, extensão e a integração entre todos os atores envolvidos. (DOSSA; SEGATO, 2010; ETZKOWITZ; LEYDESDORFF, 2000).

A Teoria da Hélice Tripla foi desenvolvida, a partir de 1996, pelos sociólogos Henry Etzkowitz e Loet Leydesdorff, baseada na perspectiva de interações harmônicas entre a Universidade, o Governo e a Empresa (setor produtivo de bens e serviços), que representariam as três pás da hélice (ETZKOWITZ; LEYDESDORFF, 2000).

A missão da Universidade, além da tradicional formadora de mão de obra, geradora de conhecimento científico e de inovação tecnológica, passa a ser a de uma universidade empreendedora, que gera o desenvolvimento econômico. Ao Governo cabe o papel de regulador e fomentador da atividade econômica, além de ser 0 ator que incentiva o desenvolvimento das inovações como forma de se atingir o desenvolvimento social. Por fim, a Empresa tem o papel de ser o "lócus" onde a inovação é desenvolvida e repassada à sociedade. Como o governo, a Empresa também atua como fomentadora das atividades desenvolvidas no âmbito da Universidade (IPIRANGA; FREITAS; PAIVA, 2010).

O atual cenário da educação do Brasil vem sofrendo sucessivas crises econômicas e políticas que resultam no desmantelamento das IES tanto na esfera pública quanto na privada. Nesse sentido, para a manutenção das atividades de pesquisa e extensão, as 
IES estão recorrendo às parcerias para continuar desenvolvendo a pesquisa como forma de proporcionar a inovação tecnológica e a extensão como forma de repassar o conhecimento da academia para a sociedade (SCHREIBER, 2013).

Na literatura é possível encontrar estudos que versam sobre os Modelos de Hélice Tripla que tratam de oportunidades para egressos do ensino superior, bem como as relações entre universidade, empresa e governo (BRISOLLA et al., 1997; PEREIRA et al, 2016), de posicionamentos estratégicos e efeitos da Hélice Tripla no desempenho de inovação (LUENGO; OBESO, 2013;

\section{MATERIAIS E METODOS}

O método de pesquisa utilizado foi o estudo de caso documental e exploratório, e a unidade de análise compreendeu documentos relativos a Programas de Extensão das duas IES. Como resultado da pesquisa, foi possível caracterizar como se apresentam as parcerias em Hélice Tripla nas IES, partindo de características apresentadas no Modelo; verificar como as parcerias beneficiam os parceiros representados
SCHREIBER et al, 2013; RODRIGUES; GAVA, 2016); Gestão Compartilhada de P\&D (POLETTO; ARAÚJO; MATA, 2011) e Cooperação Tecnológica (SEGATTO-MENDES; MENDES, 2006).

Porém, se faz necessário investigar a Hélice Tripla, levando em conta contextos regionais e locais, buscando identificar diferenças com relação aos resultados obtidos em pesquisas mais abrangentes. Outra característica dessa pesquisa é o fato de abranger duas IES diferentes, isto é, uma pública e outra privada, o que permitirá ter uma nova visão sobre os modelos de Hélice Tripla.

pelas três pás; e verificar como a sociedade é atingida pelas atividades da academia (extensão). Conclui-se que a discussão dos resultados alcançados pode contribuir para a compreensão da problemática em torno dos estudos sobre a Metodologia Hélice Tripla nas IES brasileiras.

O desenvolvimento dessa pesquisa envolveu a identificação de artigos científicos que abordavam as temáticas: "Hélice Tripla" ou "Pesquisa 
e Extensão", na base de dados Scielo,

a qual retornou nove artigos completos, conforme ilustrado na Figura 1.

Figura 1 - Hélice Tripla e pesquisa e extensão na base de dados do Scielo.

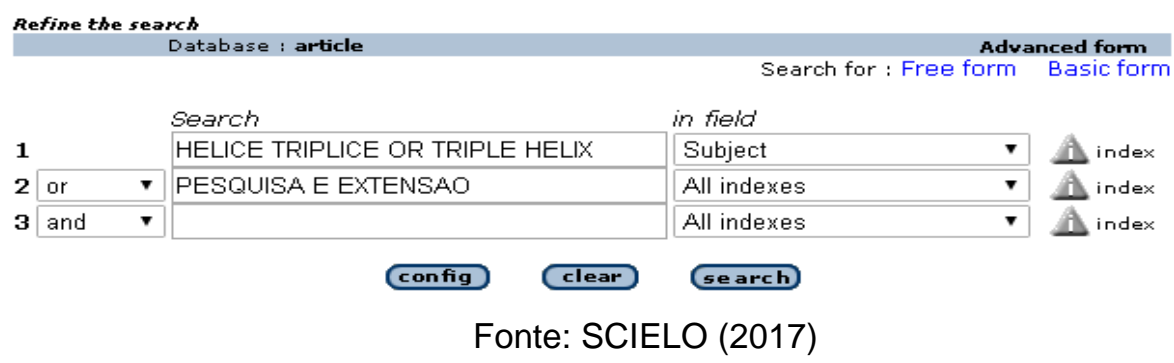

\section{RESULTADOS E DISCUSSÃO}

A seção de resultados foi inicialmente dividida em três partes: na primeira, procurou-se indícios de parcerias em Hélice Tripla na IES privada; na segunda, indícios na IES pública e por fim, montou-se o Quadro 1, disponível na Seção 3.3, adaptado

\subsection{HÉLICE TRIPLA NA IES PRIVADA}

A partir de 2012, o Centro Universitário Central Paulista - UNICEP alavancou o desenvolvimento de eventos e ações realizadas, com o propósito de criar oportunidades de ganho educacional e cultural perante a evolução dos estudantes, atrelando a crescente necessidade da comunidade em diversos segmentos. Deste modo, as diversas atividades já realizadas, foram de IPIRANGA; FREITAS; PAIVA (2010), que mostra os diversos contextos e formas de cooperação em Hélice Tripla.

incrementadas e novas foram sendo planejadas e desenvolvidas, de modo que a interação entre direção, colaboradores, docentes e estudantes evoluiu de tal modo que os próprios estudantes realizem propostas de atividades de extensão e os números de alunos participantes, ilustrado na Figura 2, demonstra esta situação. 
Figura 2 - Público atendido e alunos envolvidos em atividades de extensão no UNICEP.
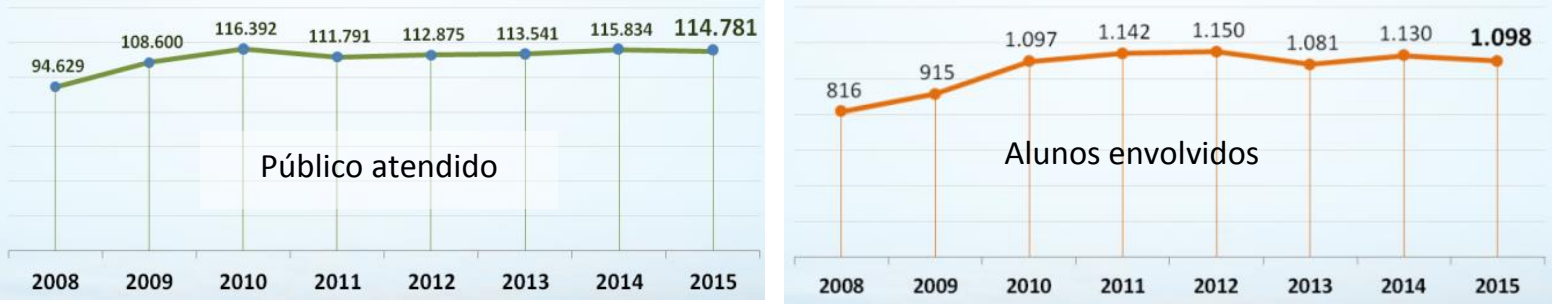

Fonte: UNICEP (2017)

A partir de 2017, com a consolidação de determinadas ações e projetos, as atividades de extensão foram expandidas com o intuito de proporcionar uma maior amplitude nas áreas de conhecimento, principalmente junto ao desenvolvimento conjunto de coordenações, corpo docente e estudantes, com ênfase na multidisciplinaridade e agregação contínua de conhecimento.

No sentido de estar em sintonia com o atual processo de globalização, que torna os mercados competitivos, o UNICEP visando preparar melhor seus futuros profissionais, desenvolveu 0 Programa de Banco de Empregos, que vêm beneficiando muitos alunos e também empresas de São Carlos e região, conforme ilustrado no Gráfico 1 , através do intercâmbio entre empresas e alunos, desde o ano de 1995. É um programa de prestação de serviços (assessoria) que tem por finalidade criar oportunidades de estágios e eventualmente empregos aos estudantes do UNICEP, bem como auxiliar as empresas de São Carlos e região no recrutamento e seleção de profissionais competentes, bem como gerir e coordenar toda a documentação envolvida, quanto a estágios não obrigatórios.

O objetivo principal do Banco de Empregos-UNICEP é o de inserir os alunos no mercado de trabalho, sem cobrança de taxas e permitir que 0 estudante aplique seus conhecimentos teóricos através da vivência em situações reais do exercício da futura profissão. Anualmente os estudantes são beneficiados, e a instituição tem a cultura de absorção para o quadro de colaboradores, dos estudantes que se destacam durante 0 estágio, possibilitando a oportunidade de desenvolvimento de carreira no próprio UNICEP. 
Gráfico 1 - Empresas conveniadas ao longo de 23 anos através de convênios de estágio não obrigatório.

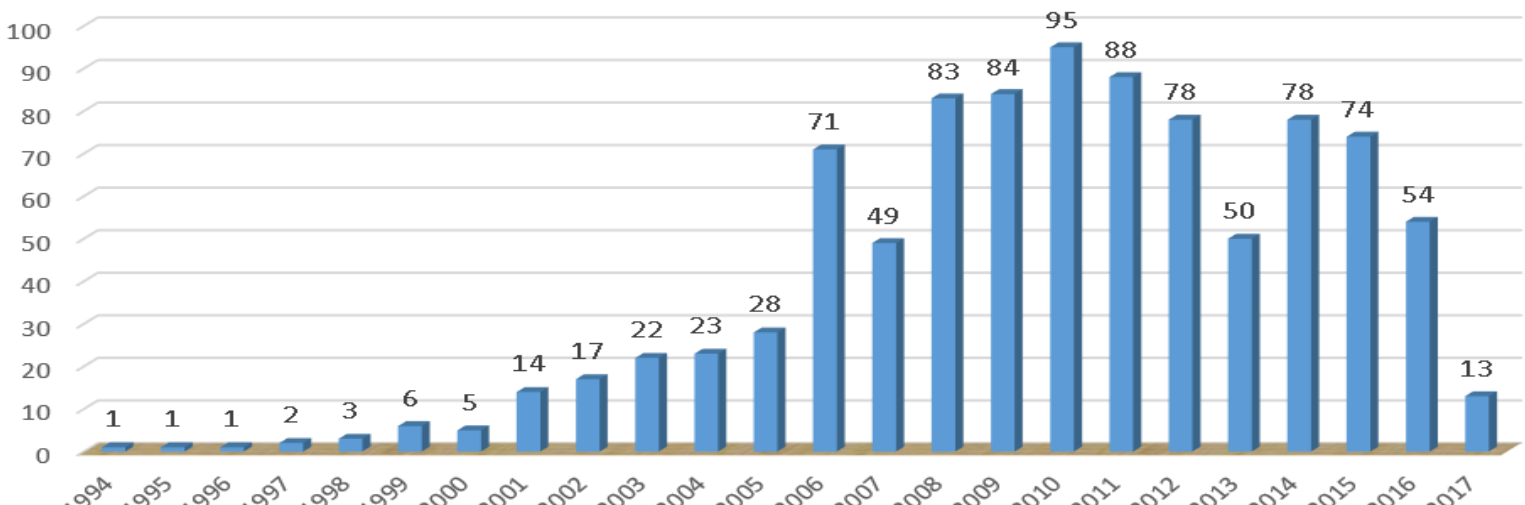

Fonte: UNICEP (2017)

Após a prévia identificação de necessidades, a elaboração de ações junto às coordenações de curso, docentes e discentes, agrega-se 0 conteúdo trabalhado, com a prática profissional.
O Gráfico 2 ilustra o Total de solicitações de estagiários da graduação realizadas pelas empresas em 2016.

Gráfico 2 - Solicitações de estagiários da graduação realizadas pelas empresas em 2016.

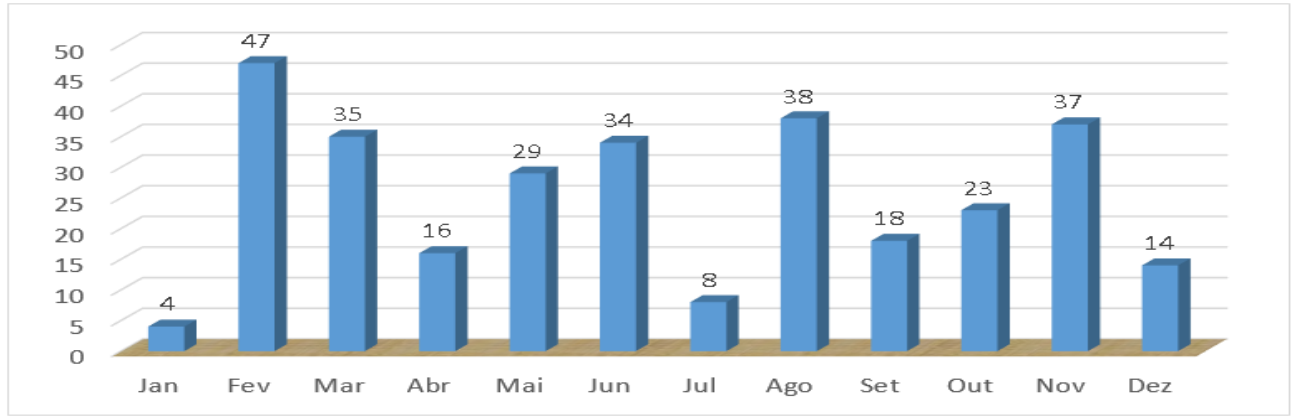

Fonte: UNICEP (2017)

Por outro lado, as IES legalmente não necessitam incluir em particulares, especialmente faculdades seus afazeres acadêmicos a pesquisa isoladas e centros universitários, que e a extensão, promovem outro tipo de 
parceria com o Estado. O Programa Universidade Para Todos (ProUni), instituído pela Medida Provisória $\mathrm{n}^{\circ}$ 213, de 10 de setembro de 2004 (BRASIL, 2004), foi destinado à concessão de bolsas de estudos parciais e integrais para cursos de graduação e sequências de formação específica, em IES particulares com ou sem fins lucrativos, mediante a isenção de certos tributos.

Entre as justificativas para a transferência de recursos públicos para as IES particulares foi promover, via ProUni, uma diluição da fronteira entre o público e o privado, pois transformaria estas IES em instituições de "interesse

\subsection{HÉLICE TRIPLA NA IES PÚBLICA}

Em seu Plano de Desenvolvimento Institucional (PDI, 2013), a Universidade Federal de São Carlos (UFSCar) reafirma seus compromissos através de uma lista de princípios que expressam a razão de ser da instituição, seus valores e sua missão. Evidente que a UFSCar como uma IES pública está submetida ao financiamento do Estado através de repasses de Recursos do Tesouro Nacional (RTN). No entanto, nos últimos anos, o ensino superior público público com finalidade social" (BRASIL, 2004). Com isso, esperar-se-ia que as IES beneficiadas, de alguma forma, pudessem retornar à sociedade algum benefício relacionado conhecimento ou produtos produzidos dentro de seus muros.

Em relação à IES particular abordada neste artigo, conforme será mostrado no Quadro 1 da seção 3.3, é possível observar que a mesma está envolvida numa série de parcerias para a prestação de serviços em áreas relacionadas aos seus cursos de graduação, além de parcerias para atividades culturais e esportivas.

vem sofrendo com as mudanças no papel do Estado, que passa a ser regulador, avaliador e controlador, disponibilizando cada vez menos recursos às universidades, como destaca Chauí (2000).

Uma alternativa para superar esta nova condição desfavorável em relação ao financiamento das atividades de ensino, pesquisa e extensão, papel primordial da universidade pública, é o estabelecimento de parcerias, não só 
com as agências governamentais de fomento à IES públicas, mas àquelas que promovem a parceria entre a universidade, a empresa e o governo, caracterizada pelas parcerias Hélice Tripla.

$\mathrm{Na}$ primeira metade dos anos 1990, estava evidente a evolução da pesquisa na UFSCar, alavancado pelos programas de pós-graduação que também cresciam não só quantitativamente, mas também qualitativamente. Como consequência do crescimento nas atividades de pesquisa, poderíamos destacar: a parceria entre os pesquisadores da UFSCar com outras instituições, nacionais e internacionais, para a produção de artigos científicos; a geração de mão de obra qualificada; a produção de bens e serviços destinados à sociedade ou de interesse de empresas privadas; e, consequência este último, o crescimento das atividades de extensão.
Este cenário propiciou o crescimento de parcerias de diversos tipos e finalidades celebradas entre a universidade, que tinha as condições para o desenvolvimento das pesquisas, as empresas que demandavam algum tipo de necessidade da academia e tinham poder de financiamento, e do governo que fazia a regulação para que estas parcerias constituíssem o instrumento legal para o desenvolvimento da inovação tecnológica para benefício da sociedade.

A Tabela 1 apresenta, no período de 2012 a 2016, o quantitativo de projetos e o respectivo volume financeiro gerenciados pela FAlUFSCar. Estes projetos tem a sua origem na Pró-Reitoria de Extensão (ProEx), na Pró-Reitoria de Pesquisa (ProPQ), na Pró-Reitoria de PósGraduação (ProPG) e na Pró-Reitoria de Graduação ProGrad).

Tabela 1 - Projetos e recursos gerenciados pela FAI-UFSCar.

\begin{tabular}{lccccc}
\hline & $\mathbf{2 0 1 2}$ & $\mathbf{2 0 1 3}$ & $\mathbf{2 0 1 4}$ & $\mathbf{2 0 1 5}$ & $\mathbf{2 0 1 6}$ \\
\hline Projetos & 293 & 250 & 239 & 116 & 470 \\
Recursos (em milhões de Reais) & 58,3 & 69,7 & 64,0 & 65,4 & 87,7 \\
\hline
\end{tabular}

Fonte: FAI-UFSCar-Transparência (2017)

Importante notar o crescimento em torno de $25 \%$ nos recursos captados com as parcerias celebradas pelos pesquisadores da UFSCar. Os 
recursos financiaram pesquisas desenvolvidas em todos os centros acadêmicos da instituição que envolve áreas do conhecimento como engenharia, saúde, educação e tecnologia. Esta heterogeneidade ajuda a explicar a flutuação do número de projetos apresentados na Tabela 2, onde o contexto financeiro pode levar as pequenas empresas a não procurar as parcerias com a instituição.
Os Projetos Governamentais e os Convênios de Cooperação Institucionais geram grande número de parcerias que, em sua maioria, está vinculada à Pró-Reitoria de Extensão. $\mathrm{Na}$ Tabela 2 pode-se observar a quantidade destas parcerias e as modalidades.

Tabela 2 - Atividades de extensão realizadas com parceiros externos.

\begin{tabular}{lccccc}
\hline \multicolumn{1}{c}{ Modalidade $^{1}$} & $\mathbf{2 0 1 2}$ & $\mathbf{2 0 1 3}$ & $\mathbf{2 0 1 4}$ & $\mathbf{2 0 1 5}$ & $\mathbf{2 0 1 6}$ \\
\hline $\begin{array}{l}\text { Atividades de extensão realizadas } \\
\text { com financiamento dos parceiros }\end{array}$ & 325 & 376 & 359 & 341 & 359 \\
$\begin{array}{l}\text { Atividades extensão realizadas sem } \\
\text { financiamento dos parceiros }\end{array}$ & 179 & 189 & 178 & 215 & 218 \\
\begin{tabular}{l} 
Consultorias / Assessorias \\
\hline
\end{tabular} & 136 & 129 & 109 & 117 & 115 \\
\hline
\end{tabular}

4. Fonte: UFSCar - Sistema ProExWeb (2017)

Uma breve análise desta Tabela 2 aponta que as atividades com parcerias que envolvem aporte financeiro, no período mantiveram uma média de 352 parcerias. Por outro lado, as parcerias que não envolvem aporte financeiro tiveram, no período, um crescimento de $21,8 \%$, indicando que a instituição, de caráter público, vem cumprindo o seu papel no sentido de levar à sociedade o conhecimento e os produtos que foram resultado das pesquisas desenvolvidas dentro de seus muros.

Também, conforme informação do sitio da Pró-Reitoria de Pesquisa, no período de 2016 a 2016, sob a responsabilidade da ProPQ, foram firmados 51 convênios de parcerias em pesquisas com instituições de ensino do Brasil e do Exterior, sendo

\footnotetext{
${ }^{1}$ No período 2012-2016 também foram realizadas 1.050 atividades classificadas com Congressos e Workshops que envolveram parceiros externos.
}

Rev. Cereus, v. 9, n. 2, p.81-97, set-dez./2017, UnirG, Gurupi, TO, Brasil. 
45 com instituições do exterior. Da mesma, com informações do sitio da Pró-Reitoria de Pós-Graduação, a UFSCar mantém convênios com 107 instituições de ensino e pesquisa, abrangendo todos os continentes, com a finalidade enviar e receber discentes em fase de pesquisa para mestrado, doutorado e pósdoutorado, conforme Tabela 3.

Tabela 3 - Alunos de pós-graduação em movimentação.

\begin{tabular}{lccccc}
\hline \multicolumn{1}{c}{ Modalidade } & $\mathbf{2 0 1 2}$ & $\mathbf{2 0 1 3}$ & $\mathbf{2 0 1 4}$ & $\mathbf{2 0 1 5}$ & $\mathbf{2 0 1 6}$ \\
\hline Recebidos do exterior & 130 & 145 & 159 & 183 & 211 \\
Enviados ao exterior & 5 & 19 & 21 & 45 & 11
\end{tabular}

Fonte: UFSCar - Sistema ProPGWeb (2017)

Era de se esperar que a totalidade dos projetos, parcerias e, principalmente, o montante de recursos financeiros investidos no ensino, na pesquisa de ponta, visto nas Tabelas 2 e 3, resultasse em inovação tecnológica produzida na instituição. Assim, a Tabela 4 apresenta uma série de produtos, processos e serviços que foram desenvolvidos na UFSCar e registrados pela Agência de Inovação UFSCar, que tem como meta reforçar o potencial inovador e empreendedor da instituição.

A Tabela 4 mostra que, no período, foram contatadas 398 empresas, possíveis parceiras no desenvolvimento de inovação. Foram registrados 395 produtos, processos ou serviços que geram um total de $R \$$ 2.782.500,00 aproximadamente. Apesar de não aparecerem registros no período, Licenciamento de Marcas e Licenciamento de Programas de Computador geram em royalties, em 2016, um total de aproximadamente $\mathrm{R} \$$ $27.800,00$.

Para a Universidade, o desenvolvimento das atividades fim da instituição, com a consequente produção e disponibilização do conhecimento, evidencia o papel de promotora da inovação tecnológica. Também fica bem definido o papel social que caracteriza uma universidade pública. Às empresas, o trabalho desenvolvido nas universidades proporciona a criação de mão de obra especializada e o desenvolvimento de produtos do interesse das mesmas. Por fim, ao governo, com seu papel regulador e incentivador da inovação, viria nas parcerias um alívio no desembolso de 
recursos para o financiamento das IES

públicas.

Tabela 4 - Transferências tecnológicas registradas na Agência de Inovação.

\begin{tabular}{lccccc}
\hline \multicolumn{1}{c}{ Modalidade } & $\mathbf{2 0 1 3}$ & $\mathbf{2 0 1 4}$ & $\mathbf{2 0 1 5}$ & $\mathbf{2 0 1 6}$ & Soma \\
\hline Licenciamento de patentes & 1 & 0 & 4 & 1 & 6 \\
Empresas criadas (Spin-offs) & 0 & 0 & 3 & 1 & 4 \\
Licenciamento de cultivares cana & 97 & 90 & 90 & 94 & 371 \\
Licenciamento de cultivares alface & 9 & 3 & 2 & 0 & 14 \\
Empresas contatadas & 0 & 0 & 306 & 92 & 398 \\
$\quad$ Royalties (em mil reais) & & & & & \\
Patentes & - & 8,7 & - & 5,5 & 14,2 \\
Cultivares cana & 655,2 & 734,2 & 794,1 & 502,3 & $2.685,8$ \\
Cultivares alface & 0 & 7,5 & 44,5 & 30,5 & 82,5 \\
\hline
\end{tabular}

Fonte: Adaptado do Relatório de Gestão 2013-2016 - Aln (2017)

\subsection{HÉLICE TRIPLA EM IES PÚBLICA E PRIVADA}

A partir da análise do referencial teórico e levantamento de dados, foi possível elaborar o Quadro 1, que mostra alguns exemplos de atividades

\section{CONSIDERAÇÕES FINAIS}

A partir do quadro teórico relacionado aos estudos CTS, mais especificamente 0 Construtivismo Social, a presente pesquisa procurou verificar como ocorre a interação entre a Universidade, a Empresa, e o Governo em IES nas esferas pública e privada de São Carlos, "norteados por um objetivo comum, que é o desenvolvimento da pesquisa, desenvolvidas entre as Instituições de Ensino Superior Públicas e Privadas, no tocante ao Modelo de Hélice Tripla. extensão e a integração entre todos os atores envolvidos". (ETZKOWITZ; LEYDESDORFF, 2000). O Modelo de Hélice Tripla é baseado na perspectiva de interações harmônicas entre os três atores, destacando, por um lado, as características de cada ator e, por outro lado, os interesses comuns que pode surgir da interação. Destaca-se que o momento econômico e político em que 
estão inseridas as IES, resultam no desmantelamento destas instituições tanto na esfera pública quanto na privada. Neste contexto regional, verifica-se que são importantes as parcerias em Hélice Tripla no sentido de continuar o desenvolvimento das atividades fins das instituições, ou seja, as atividades de ensino e extensão das privadas e, nas públicas, as atividades de ensino, pesquisa e extensão, em ambos os casos, proporcionando o repasse do conhecimento da academia à sociedade. No caso da IES pública, ficou evidente que as parcerias foram importantes e resultaram em aporte financeiro que proporcionou 0 desenvolvimento de serviços, processo e produtos que acabaram chegando à sociedade. No caso da IES privada, as parcerias proporcionaram à sociedade, através da parceria com o governo, a possibilidade do acesso ao ensino superior, além das atividades de extensão que chegaram à sociedade.
Através da presente pesquisa foi possível verificar, não só a ocorrência de parcerias em Hélice Tripla nas IES, mas que estas parcerias foram positivas para os três atores envolvidos, além da sociedade de modo geral, que se beneficiou com o repasse do conhecimento vindo da academia. Por outro lado, o método de pesquisa enfrentou limitações, pois focou apenas em duas Instituições de Ensino Superior e, pela limitação de tempo, inviabilizou a análise mais abrangente de um significativo número de Instituições, bem como a análise de artigos sobre o tema de Hélice Tripla. Futuras pesquisas poderiam ampliar a amostra analisada e comparar os resultados aqui alcançados com os resultados advindos das publicações científicas que versam sobre a temática, em especial sobre a correlação de indícios de Hélice Tripla nas IES analisadas. 


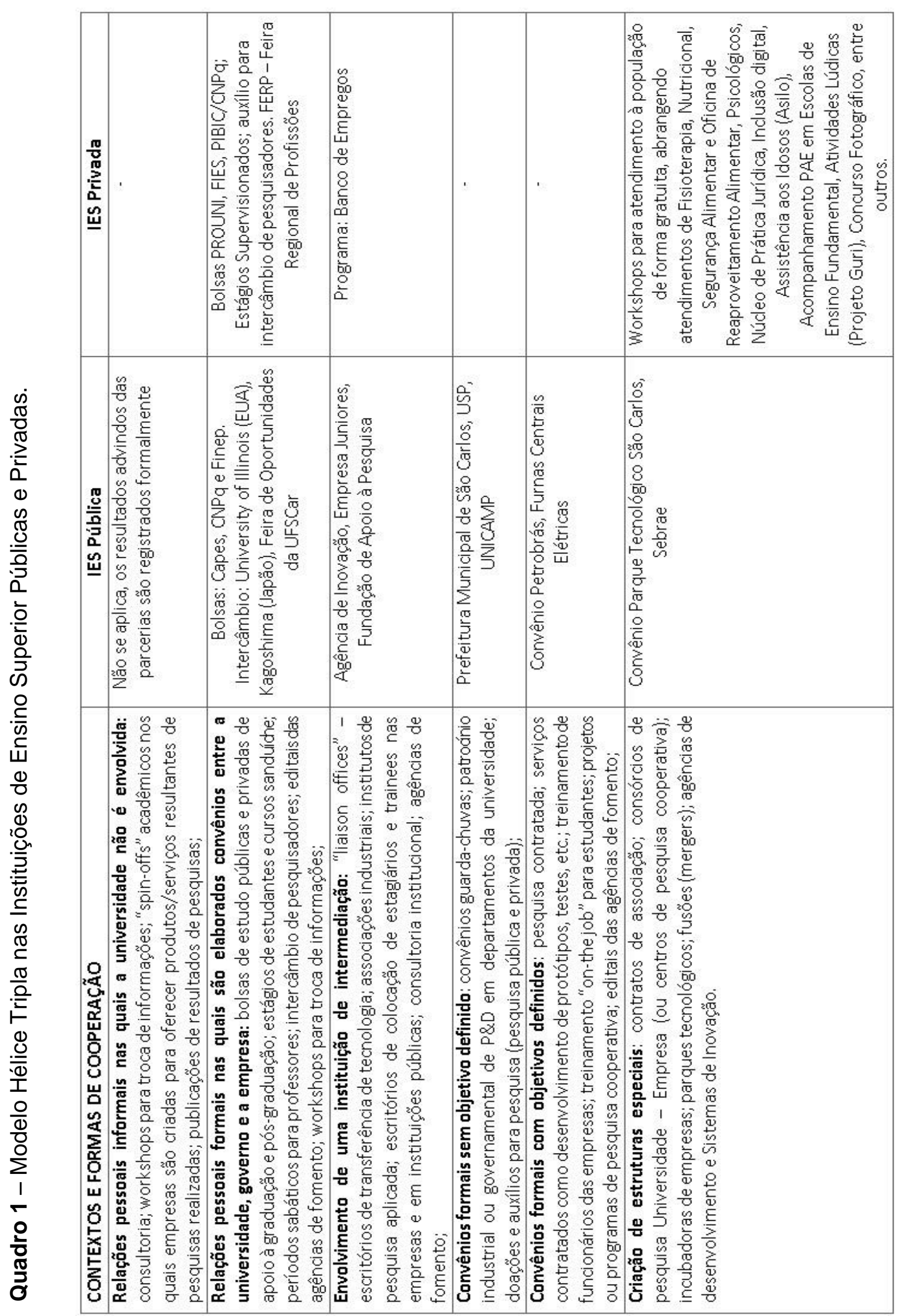

Rev. Cereus, v. 9, n. 2, p.81-97, set-dez./2017, UnirG, Gurupi, TO, Brasil. 


\section{REFERÊNCIAS}

Aln. Agência de Inovação UFSCar 2016. Disponível em: $<$ http://www.inovacao.ufscar.br/images/relatorios/relatoriog2013-2016.pdf>. Acesso em 20/07/2017.

BRASIL. Ministério da Educação. Medida Provisória n. 213, de 10 de setembro de 2004. Institui o Programa Universidade para Todos - PROUNI, regula a atuação de entidades beneficentes de assistência social no ensino superior, e dá outras providências. 2004. Disponível em: <http://www.mec.gov.br>. Acesso em: 20/07/2017.

BRISOLLA, Sandra et al. As relações universidade-empresa-governo: um estudo sobre a Universidade Estadual de Campinas (UNICAMP). Educ. Soc., Campinas, v. 18, n. 61, p. 187-209, Dez. 1997.

CHAUÍ, Marilena. A universidade em ruínas. In: TRINDADE, Hélgio (Org.). Universidade em ruínas na república dos professores. 2 ed. Rio de Janeiro: Vozes, 2000.

DOSSA, Alvaro Augusto; SEGATTO, Andréa Paula. Pesquisas cooperativas entre universidades e institutos públicos no setor agropecuário brasileiro: um estudo na Embrapa. Rev. Adm. Pública, Rio de Janeiro, v. 44, n. 6, p. 1327-1352, Dez. 2010.

ETZKOWITZ, Henry; LEYDESDORFF, Loet. The dynamics of innovation: from National Systems and "Mode 2" to a Triple Helix of university-industry-government relations. Research Policy, v. 29, p. 109-123, 2000.

IPIRANGA, Ana Sílvia Rocha; FREITAS, Ana Augusta Ferreira de; PAIVA, Thiago Alves. O empreendedorismo acadêmico no contexto da interação Universidade Empresa - Governo. Cad. EBAPE.BR, Rio de Janeiro, v. 8, n. 4, p. 676-693, dez. 2010.

LUENGO, María Jesús; OBESO, Maria. El efecto de la triple hélice en los resultados de innovación. Rev. adm. empres., São Paulo , v. 53, n. 4, p. 388-399, Ago. 2013.

PDI - Plano de Desenvolvimento Institucional - UFSCar, 2013. Disponível em: http://www.pdi.ufscar.br/pdi-2004. Acesso em: 31/07/2017.

PEREIRA, Giveldna Maria Costa et al. Panorama de oportunidades para os egressos do ensino superior no Brasil: o papel da inovação na criação de novos mercados de trabalho. Ensaio: aval. pol. públ. Educ., Rio de Janeiro, v. 24, n. 90, p. 179-198, Mar. 2016.

POLETTO, Carlos Alberto; ARAUJO, Maria Arlete Duarte de; MATA, Wilson da. Gestão compartilhada de P\&D: o caso da Petrobras e a UFRN. Rev. Adm. Pública, Rio de Janeiro, v. 45, n. 4, p. 1095- 1117, Ago. 2011.

RODRIGUES, Flávia Couto Ruback; GAVA, Rodrigo. Capacidade de apoio à inovação dos Institutos Federais e das Universidades Federais no Estado de Minas Gerais: um 
estudo comparativo. REAd. Rev. eletrôn. adm. (Porto Alegre), Porto Alegre, v. 22, n. 1, p. 26-51, Apr. 2016.

SCHREIBER, Dusan et al. Posicionamento estratégico de MPE'S com base na inovação através do modelo Hélice Tríplice. REAd. Rev. eletrôn. adm. (Porto Alegre), Porto Alegre, v. 19, n. 3, p. 767-795, dez. 2013.

SEGATTO-MENDES, Andréa Paula; MENDES, Nathan. Cooperação tecnológica universidade-empresa para eficiência energética: um estudo de caso. Rev. adm. contemp., Curitiba , v. 10, n. spe, p. 53-75, 2006.

UNICEP. Banco de Empregos. 2017. Disponível em: <http://www.unicep.edu.br/ bancodeempregos/>. Acesso em: 25/08/2017.

Recebido em: 29/08/2017

Aprovado em: 18/10/2017 